\title{
Yeast biofilm in food realms: occurrence and control
}

\author{
Giacomo Zara $^{1} \cdot$ Marilena Budroni $^{1} \cdot$ Ilaria Mannazzu ${ }^{1} \cdot$ Francesco Fancello $^{1} \cdot$ Severino Zara ${ }^{1}$ (])
}

Received: 17 June 2020 / Accepted: 4 August 2020 / Published online: 10 August 2020

(c) The Author(s) 2020

\begin{abstract}
In natural environments, microorganisms form microbial aggregates called biofilms able to adhere to a multitude of different surfaces. Yeasts make no exception to this rule, being able to form biofilms in a plethora of environmental niches. In food realms, yeast biofilms may cause major problems due to their alterative activities. In addition, yeast biofilms are tenacious structures difficult to eradicate or treat with the current arsenal of antifungal agents. Thus, much effort is being made to develop novel approaches to prevent and disrupt yeast biofilms, for example through the use of natural antimicrobials or small molecules with both inhibiting and dispersing properties. The aim of this review is to provide a synopsis of the most recent literature on yeast biofilms regarding: (i) biofilm formation mechanisms; (ii) occurrence in food and in food-related environments; and (iii) inhibition and dispersal using natural compounds, in particular.
\end{abstract}

Keywords Adhesion · Biofilm · Candida spp. Extracellular matrix · Polyphenols · Quorum sensing · Saccharomyces cerevisiae

\section{Yeast biofilm}

The ability of fungal species to adhere to and grow on different substrates or hosts is surprisingly broad: from human and plant tissues to food matrices, fuel lines, and even bare rocks (Fanning and Mitchell 2012; Rola et al. 2016). Most of the knowledge accumulated on fungal biofilms has been stimulated by the implications of fungi, such as Cryptococcus, Aspergillus, Pneumocystis, Coccidioides in human pathogenesis (Fanning and Mitchell 2012). Similarly, health issues related to the development of the yeast Candida albicans have stimulated the study of yeast biofilms (Lohse et al. 2018). An imprecise distinction has been made between yeasts and those dimorphic filamentous fungi that often produce abundant yeast-like growth. Notwithstanding this possible confusion, yeasts, whether ascomycetes or basidiomycetes, have been defined as single-cell microorganisms generally characterized by budding or fission as the primary means of asexual reproduction, and having sexual states that

Giacomo Zara

gzara@uniss.it

Severino Zara

szara@uniss.it

1 Department of Agricultural Sciences, University of Sassari, Sassari, Italy are not enclosed in fruiting bodies (Kurtzman et al. 2011). As with other microbial biofilms, that produced by yeast is a highly structured microbial community associated with or attached to a surface, upon which the microbial cells enclose themselves within a self-produced extracellular matrix (Wu et al. 2017). Yeast beneficial biofilms in the food realm have been also described, mostly in relation to Saccharomyces cerevisiae, such as those required for the ageing and maturation of special wines, fermented olives and dairy products.

\section{Genetic determinants of yeast biofilm formation}

In the first step of biofilm formation, yeast cells adhere to each other and to both biotic and abiotic surfaces (Bojsen et al. 2012). Cell attachment is mediated by specific adhesion molecules, called adhesins, through amyloid-like or hydrophobic interactions (Lipke 2018). In S. cerevisiae, different proteins have been described that are involved in biofilm formation, including Flo11p (Zara et al. 2005), Hsp12p (Zara et al. 2002), Ccw14p (Moreno-García et al. 2018), Fig. 2p (Van Mulders et al. 2010), etc. Of these, Flo11p is directly involved in biofilm formation on solid or semisolid agar, on plastic surfaces, and on the air-liquid interface (Reynolds and Fink 2001; Zara et al. 2005). Differences in the biofilmforming ability of $S$. cerevisiae strains have been related to the number of repeated sequences and the transcriptional 
levels of FLO11 (Zara et al. 2009). FLO11 transcription responds to nutritional and environmental stimuli through signals that activate different pathways, including the MAPK cascade, the cAMP-PKA pathway, and the TOR pathway, as well as the Cyc8p/Tup1p complex (Vinod et al. 2008; Nguyen et al. 2018). Whole-genome resequencing has enabled 155 loci to be identified that are highly divergent between $110 \mathrm{~S}$. cerevisiae strains able to form biofilm vs. those unable to do so (Coi et al. 2017). These loci include the major regulators cAMP, IRAl, and the MAP-kinases STE7, KDX1, and RGA2. In Candida, the major regulatory mechanisms governing biofilm development involve both the MAPK and cAMP pathways, as well as transcriptional regulators such as Bcr1p and Tec1p (Gulati and Nobile 2016; Fox et al. 2015).

Once yeasts cells have started to adhere to each other and to a surface, they proliferate, grow into filamentous forms (hyphae and pseudohyphae), and accumulate an extracellular matrix (ECM) (Vopálenská et al. 2010). Cells capable of forming a network of hyphae/pseudohyphae display stronger attachment to inert surfaces (e.g. stainless steel and plastic). In particular, the pseudohyphal content is directly correlated with biofilm strength and resistance, probably due to the higher amount of chitin in pseudohyphal cells (Paramonova et al. 2009). ECM is commonly made of carbohydrate, protein, lipid, and nucleic acid (Flemming and Wingender 2010; Faria-Oliveira et al. 2015). Karunanithi et al. (2010) suggested that in mature biofilms of $S$. cerevisiae, Flo11p forms part of the ECM, where it promotes a kind of cellular lubrication phenomenon that facilitates cellular motility. The ECM confers yeast cells a broad range of advantages, such as adhesion, cohesion, and mechanical properties, nutritional sources, enzymatic activities, and protection (Flemming and Wingender 2010) (Fig. 1).
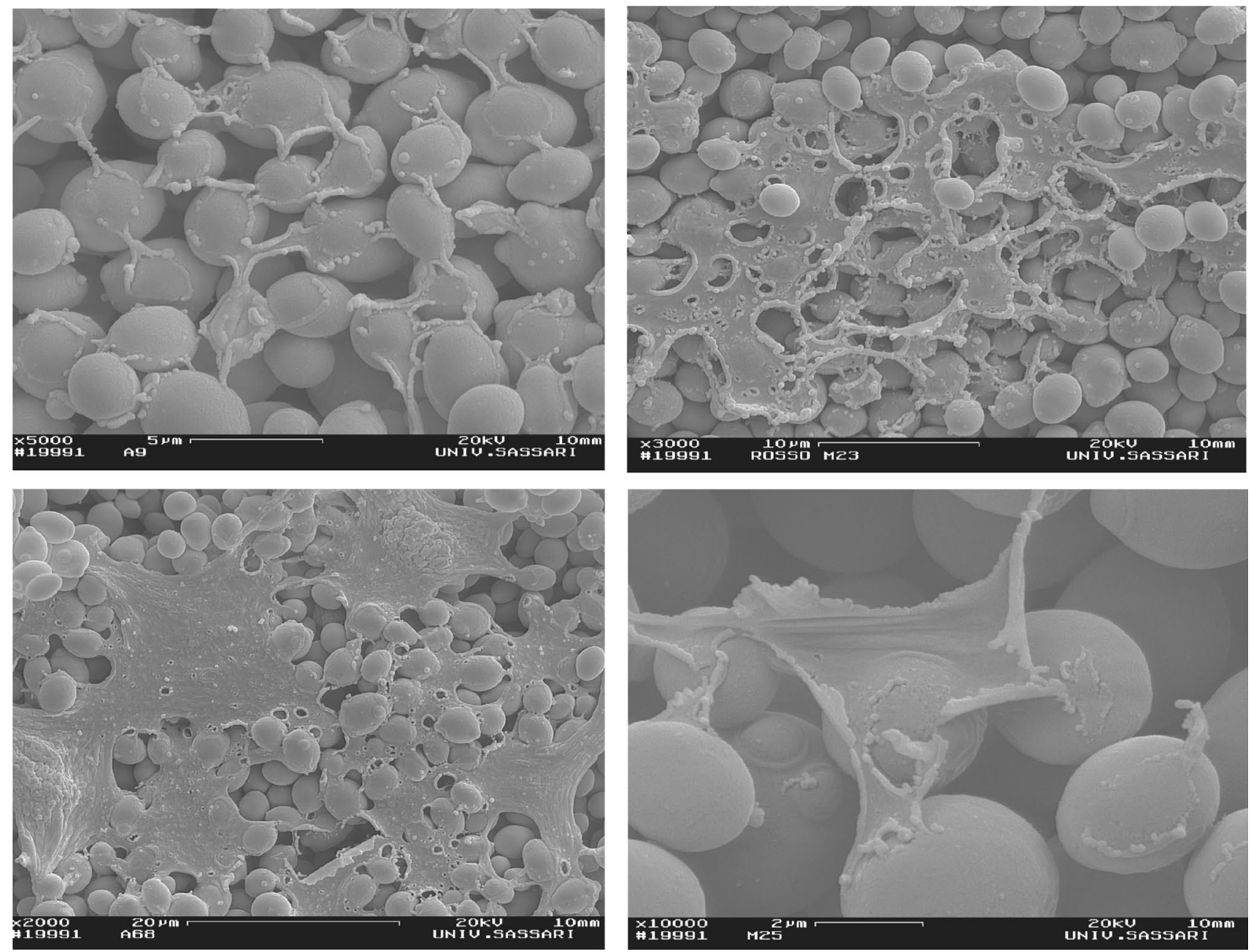

Fig. 1 Extracellular matrix from different $S$. cerevisiae biofilm-forming yeast 


\section{Nutritional factors that induce yeast biofilm formation}

In most cases, the availability of nutrients, such as carbon and nitrogen sources, but also lipids, controls biofilm development. In S. cerevisiae, the ammonia permease Mep2p activates the MAPK and the CAMP-PKA pathways when low concentrations of diammonium phosphate are available (Vinod et al. 2008). Furthermore, TOR pathway activity switches off in response to increasing nitrogen concentrations (Vinod et al. 2008). Thus, biofilm formation and FLO11 gene expression are enhanced in S. cerevisiae when nitrogen sources are scarce (Zara et al. 2011). Similarly, glucose starvation increases biofilm formation and FLO11 expression through the cAMP-PKA and SNF1 pathways (Livas et al. 2011; Bojsen et al. 2012). Van Nguyen et al. (2020) reported that the inhibition of biofilm formation at high glucose concentration is mediated by increased Cyc8pmediated FLO11 repression. Zara et al. (2010) suggested that biofilm formation requires an energy input provided by reduced carbon sources. Indeed, greater biofilm formation was obtained by growing $S$. cerevisiae on glycerol, ethyl acetate, and ethanol. In addition to carbon and nitrogen compounds, lipids also play a major role in biofilm formation. In particular, the fatty acid residues of biofilm-forming strains of S. cerevisiae were shown to have a larger medium chain length and higher unsaturation levels than those in non-film-forming strains (Zara et al. 2008). Zara et al. (2012) found that cerulenin, an inhibitor of the fatty acid synthase complex, prevents biofilm formation and FLO11 transcription. Whole transcriptomic analysis revealed that a lack of lipid nutrients induces a stress response in biofilmforming strains, leading to the induction of PAUs and HSPs gene families (Zara et al. 2019b). Similarly, biofilm cells of C. albicans differ from planktonic cells in their phospholipid, sterol, and sphingolipid content (Lattif et al. 2011). In accordance, sterol, fatty acid, and lipid metabolism pathways were found to be upregulated during biofilm formation (Lattif et al. 2008).

\section{Yeast biofilm in food realms}

Yeast are found in a range of fresh and processed foods: dairy, meat, fruit and vegetable products, syrups, honey, juices, soft drinks, alcoholic beverages, salad dressings, mayonnaise, confectioneries, jams, and bread (Deák 1991). The main source of microbial contamination in the production chain may be the processing plant itself, due to inadequate hygiene measures that can favor the formation of biofilms. Yeast contamination in food processing plants is likely due to aerosols and to splash and overspray during sanitation programs (Snyder and Worobo 2018). High levels of spoilage yeasts have also been found in floor drains (Snyder and Worobo 2018). An abundant growth of unwanted yeast, such as Brettanomyces bruxellensis, Candida krusei, Candida parapsilosis, Debaryomyces hansenii, Kloeckera apiculata, Pichia membranaefaciens, Rhodotorula mucilaginosa, S. cerevisiae, Schizosaccharomyces pombe, Torulopsis holmii, and Zygosaccharomyces bailii, can lead to problems in food quality and safety (Salo and Wirtanen 2005). In addition, many yeast species can develop as biofilm cells that are significantly more difficult to eradicate than planktonic cells (Brugnoni et al. 2007). Indeed, microbial biofilms cost the food industry several billion dollars every year due to product losses, reduced heat transfer, increased fuel consumption, and the excessive use of chemical agents for their control and removal (Chambers et al. 2006; Lyon et al. 2008; Srey et al. 2013). Below, some examples of how yeast biofilms spoil different foods and beverages, including drinking water, are provided (Fig. 2).

Yeasts have a central role in the fermentation of table olives and in the development of their sensorial features. In particular, yeasts contribute to olive debittering, through the activity of $\beta$-glucosidase, to the degradation of phytic complexes, and to the release of inorganic phosphorous, due to the production of enzymes such as phosphatases and phytases. Yeasts, particularly Candida boidinii, can co-aggregate on the surface of olives together with lactic acid bacteria (LAB) and establish poly-microbial biofilms (Arroyo-López et al. 2012; Benítez-Cabello et al. 2015). Recently, the presence of biofilm-forming yeast such as Candida spp. and Pichia spp. was also observed in olive oil by Santona et al. (2018), and although biofilm-forming yeast can make a positive contribution to olive fermentation and maturation (Camiolo et al. 2017; Porru et al. 2018), the consequences of their presence in olive oils remains open to debate (Santona et al. 2018; Fancello et al. 2020).

Another setting in which biofilms play an important role is that of dairy products. Microbial communities can influence the quality of dairy products in both a negative or positive way. Floor drains in dairy processing facilities are one of the niches where the formation of biofilms can occur. Due to their open system, floor drains are exposed to a wide range of microbes and nutrients and may also serve as a reservoir for food-borne pathogens. In particular, Schön et al. (2016) showed that floor drain communities were dominated by product-associated bacterial (e.g. Lactobacillus kefiranofaciens, Streptococcus thermophilus) and eukaryotic phylotypes (e.g. Debaryomyces hansenii, Saccharomyces unisporus). Vitzilaiou et al. (2019) found that the reverse osmosis membrane filtration elements from a whey water filtration unit were highly contaminated by biofilm-forming microbial populations, both before and after cleaning-in-place treatments. These microbial populations consisted of the budding yeasts Sporopachydermia lactativora in association with 
Fig. 2 Negative and positive effects of yeast biofilm

\section{Yeast Biofilm in food}

\section{Negative role}

\begin{tabular}{|c|}
\hline Wine \\
C. vini \\
P. membranifaciens \\
B. bruxellensis \\
H. polymorpha \\
S. ludwigii, \\
Z. bailii, \\
S. pombe
\end{tabular}

\begin{tabular}{|c|}
\hline Dairy products \\
D. hansenii \\
S. Unisporus \\
M. spicifer \\
S. clavata \\
S. lactativora
\end{tabular}

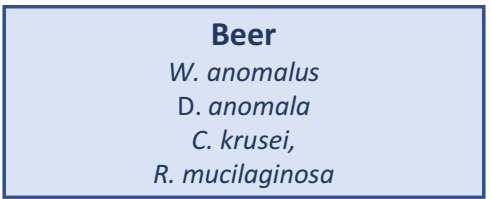

Fruit Juices

C. krusei

Zygosaccharomyces spp Candida spp

Rhodotorula spp

\section{Drinking water}

Black yeasts

\section{Positive role}

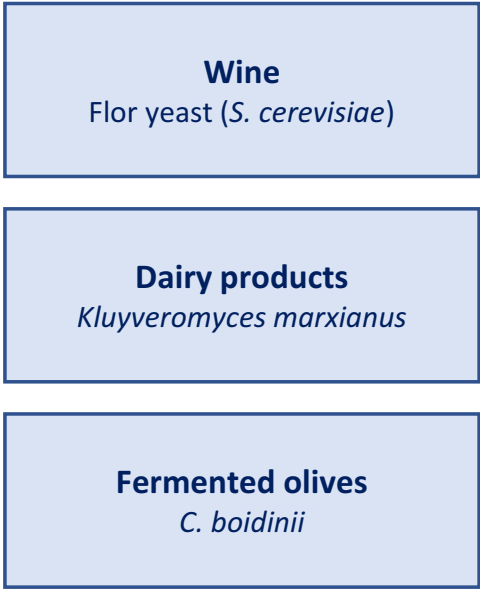

filamentous fungi (Magnusiomyces spicifer and Saprochaete clavate) and Gram-negative bacteria. In other instances, the development of a biofilm in dairy products contributes positively to the product. It has been showed that Kluyveromyces marxianus strains isolated from fermented goat's milk were able to from a biofilm, and this yeast species also performs a useful role in the maturation of 'Pecorino di Farindola' and 'Parmigiano Reggiano' cheeses (Perpetuini et al. 2018, 2019).

With regard to alcoholic beverages, yeast biofilms are also present in the wine and beer industry. In the former, a well-known example of positive yeast biofilm is that represented by $S$. cerevisiae in Sherry fino (Spain) and Sherry-like wines, such as Szamorodni (Hungary), 'Vin Jaune' (France), 'Vernaccia di Oristano' (Italy), etc. At the end of the alcoholic fermentation, the so-called "flor strains" of $S$. cerevisiae rise to the surface of the wine and switch from fermentative to the oxidative metabolism (Legras et al. 2016). Specifically, yeast oxidize ethanol to produce acetaldehyde, which is the precursor of molecules responsible for the specific sensorial properties of biologically aged wines (Pozo-Bayón and Moreno-Arribas 2011). Contrary to these beneficial biofilms, the development of other oxidative yeast species on the surface of 
wine constitutes a common problem in alcoholic beverage industry. The visual manifestation is the formation of a film resulting from the repeated budding of mother and daughter cells that remain attached, forming chains that eventually develop into a thick biofilm over the entire surface of the wine (Fugelsang and Edwards 2007). This behavior has been ascribed to Candida vini, P. membranifaciens, and Hansenula polymorpha, which produce sensorially negative compounds. Other yeast species able to form a biofilm in wine belong to the fermentative species Brettanomyces/Dekkera bruxellensis, Saccharomycodes ludwigii, Z. bailii, and S. pombe (David-Vaizant and Alexandre 2018). Their development during wine storage leads to defects such as cloudiness or haziness, sediment production, off-odors, and off-tastes. In beer, yeast biofilms constitute a negative phenomenon. In breweries, yeast can form biofilms colonizing new surfaces or existing fungal or bacterial biofilms (Gattlen et al. 2011). In particular, yeasts have a high impact on alcohol-free beer and beermixed beverages, where they can be responsible for up to $90 \%$ of the spoilage incurred (Riedl et al. 2019). These beverages are characterized by chemical properties (a high sugar content and a low $\mathrm{pH}$ ) that favors the attachment of first-stage yeast biofilm colonizers. Wickerhamomyces anomalus was reported to be the most important in the context of biofilm formation in breweries (Laitila et al. 2011). Dekkera anomala has also been reported to form biofilms in beer and wort, with strain-dependent biofilm production (Storgårds et al. 2006). C. krusei, R. mucilaginosa, P. anomala, P. membranifaciens, and $S$. cerevisiae are able to form biofilms on stainless steel surfaces and in the filling area, especially in the conveyor system near the filler (Storgårds et al. 2006). Similarly, Brettanomyces spp. are able to form a biofilm on plastic surfaces under conditions with low sugar concentrations (Joseph et al. 2007). Goode et al. (2010) investigated the efficacy of different cleaning procedures in reducing the formation of yeast biofilm in a brewery processing plant using $\mathrm{NaOH}$ based agents. However, biofilm formed of D. anomala was found to be resistant to many cleaning and disinfecting solutions, as well as antibiotics (Hutzler et al. 2012). Yeast biofilms also have a negatively effect upon fruit juice production lines. Yeast belonging to Saccharomyces, Zygosaccharomyces, Candida, and Rhodotorula spp. have all been isolated from biofilms on conveyor tracks, and on can and bottle warmers in the packaging department of fruit juice processing plants, due to their high resistance to thermal processing (Salo and Wirtanen 2005). Brugnoni et al. $(2007,2011)$ found that $C$. krusei isolated from a large-scale apple juice processing plant was capable of rapidly colonizing and covering stainless steel surfaces. Moreover, C. krusei was found in mixed biofilms subjected to varying hydrodynamic conditions commonly found in apple juice facilities (Brugnoni et al. 2014). Of particular significance, $C$. krusei biofilm was identified as potentially playing an important role in the survival and dissemination of Escherichia coli $\mathrm{O} 157: \mathrm{H} 7$ and Salmonella enterica in food-processing environments (Tarifa et al. 2017).

Finally, the negative role of yeast biofilm in drinking water systems needs to be considered. Black yeasts are commonly associated with water handling systems and form recalcitrant biofilms in filters, grates, and nozzle heads (De Hoog et al. 2006). In particular, mixed species microbial biofilms have been found in Drinking Water Distribution Systems (DWDS). DWDS are complex pipe networks that function as dynamic ecosystems where consortia of fungal-bacterial biofilms, attached to the inner pipe surfaces, are involved in a range of processes that ultimately determine the quality and safety of the delivered water. In particular, biofilm cells are responsible for the biocorrosion of metal pipes and their mobilization may affect the safety of bulk water (Husband et al. 2016).

\section{Control of yeast biofilm}

Yeast biofilms are tenacious structures difficult to eradicate and to treat with the current arsenal of antifungal agents available. As Ramage et al. (2014) pointed out, fungal biofilm resistance involves both physical barriers and regulatory processes. Many genetic determinants of antifungal resistance are involved in the formation of ECM, the upregulation of drug efflux pumps, the activation of stress responses, and the modification of general cell physiology, such as a reduced growth rate (Fanning and Mitchell 2012; Gulati and Nobile 2016). Thus, the antifungal resistance of biofilms is multifactorial and heterogeneous, often related to specific developmental phases of biofilm formation. Furthermore, ECM composition and surface density greatly influence biocide effectiveness (AlvarezOrdóñez et al. 2019). Biocides are generally employed by the food industries at concentrations the exceed the minimal inhibitory concentrations and should therefore be able to guarantee microbial inactivation. However, biocides, and other antimicrobials are less effective in inactivating microbes within biofilms than in the planktonic state (Cappitelli et al. 2014). It was reported that biofilm cells are up to 1000-fold more resistant to antifungal agents (Ramage et al. 2014). Considering the role of biofilms as a reservoir of potential spoilage and pathogenic microorganisms, much research effort is being devoted to improving the methods and strategies available to eliminate them from industrial settings or to developing novel inhibitory or removal tools that are more effective, economic, and sustainable. 


\section{Natural compounds against yeast biofilms}

Considering that the currently available antifungal agents usually have very little effect on yeast biofilms, novel active compounds derived from plants, lichens, algae, and microbes (fungi or bacteria) have been sought and described (Table 1).

Plants comprise the largest source of compounds active against fungal biofilms, particularly essential oils (EOs), which have long been recognized to have antimicrobial properties and are classified as "Generally Recognized as Safe" (GRAS) by the Food and Drug Administration (FDA). Due to their natural origin, their utilization in food formulations is supported by a positive public perception of them being a safer and more eco-friendly alternative to "synthetic agents" (Martillanes et al. 2017). EOs counteract the growth of bacteria, yeasts, and molds and have been extensively tested in vitro against a wide range of pathogenic bacteria and fungi, and in vivo for the control of potential pathogens in the animal gastrointestinal tract (Petretto et al. 2014). The activity of EOs is due to their phenolic compounds, such as coumarins, lignans, flavonoids, anthocyanins, tannins, quinines, and stilbenes. These compounds have been proven to be active against fungal biofilms and are less likely to induce resistant phenotypes. Thus, their use improves of the shelf-life of perishable products and the production of food without the use of synthetic additives. Tenore et al. (2012) showed that the polyphenolic fractions from red pitaya (Hylocereus polyrhizus) inhibited yeasts and molds. Shahzad et al. (2014) investigated the anti-biofilm activity of 14 polyphenols, of which pyrogallol (present in cocoa, coffee, and beer) and curcumin (available in common foods such as dried turmeric and curry power) displayed activity against
C. albicans biofilms. Similarly, methanol olive leave extracts, rich in polyphenols, such as oleuropein, exerted strong antibiofilm activity against $C$. albicans (Takó et al. 2020). The anti-biofilm activity of terpenes against fungi and yeast have been reported by (Girardot and Imbert 2016). More recently, the anti-biofilm activity of aldehydic terpenes against the yeast Cryptococcus neoformans was reported by Kumari et al. (2019). Another recent study showed that essential oils from clove and thyme were able to efficiently inhibit biofilm formation by 17 Candida spp. isolated from different food matrices (Rajkowska et al. 2019). Tannins are other natural molecules that can be used to inhibit fungal biofilm; these substances also exhibit antioxidant, enzymatic inhibition, antidiarrheal, and mostly antiseptic properties, hence the interest in tannins as food additives (Bruneton 1999). Alejo-Armijo et al. (2017) showed that two procyanidins isolated from a laurel wood extract inhibited the growth of $C$. albicans at high concentrations and prevented biofilm formation at lower concentrations. Glasenapp et al. (2019) showed that the hydrolysable tannin fraction of Mangrove exhibits an anti-adhesion activity against $C$. albicans. Quinones also demonstrate antibacterial and fungicidal properties (Girardot and Imbert 2016). Tsang et al. (2012) showed that the quinone purpurin was able to repress yeast-to-hyphal transition in C. albicans, downregulating the expression of hypha-specific genes. In the context of natural products, hydrosols, complex mixtures containing traces of EOs and several water-soluble components, are also of significant interest (D'Amato et al. 2018). Plant extracts with unknown composition also showed antibiofilm activity against $C$. albicans biofilm. Such was the case for fresh garlic extract, Cassia spectabilis methanol leaf and crude
Table 1 Compounds of natural origin with inhibiting activity against yeast biofilm

\begin{tabular}{|c|c|c|}
\hline Origin/compound & Yeast species & Authors \\
\hline $\begin{array}{l}\text { Red pitaya (Hylocereus polyrhizus) poly- } \\
\text { phenolic fractions }\end{array}$ & Yeasts and molds & Tenore et al. (2012) \\
\hline Cocoa, coffee, and beer polyphenols & C. albicans & Shahzad et al. (2014) \\
\hline Olive leave extracts - oleuropein & C. albicans & $\begin{array}{l}\text { Takó et al. (2020), } \\
\text { Edziri et al. (2019) }\end{array}$ \\
\hline Orange nano emulsion & S. cerevisiae & Sugumar et al. (2016) \\
\hline Aldehydic terpenes & Cryptococcus neoformans & Kumari et al. (2019) \\
\hline Clove and thyme - essential oils & Candida spp. & Rajkowska et al. (2019). \\
\hline Laurel wood extract - procyanidins & C. albicans & Alejo-Armijo et al. (2017) \\
\hline Mangrove - hydrolysable tannin & C. albicans & Glasenapp et al. (2019) \\
\hline L-histidine & S. cerevisiae & Bou Zeidan et al. (2014) \\
\hline $\begin{array}{l}\text { Arginine, lysine, cysteine, tryptophan, } \\
\text { phenylalanine, threonine }\end{array}$ & S. cerevisiae & Zara et al. (2019a) \\
\hline $\mathrm{N}$-acetyl cysteine & C. albicans & Abd et al. (2014) \\
\hline Farnesol & C. tropicalis & Agustín et al. (2019) \\
\hline Tyrosol & Candida spp. & Sebaa et al. (2019) \\
\hline Killer toxins & Candida spp. & Tan and Tay (2011) \\
\hline
\end{tabular}


extract, and methanol and ethyl acetate methanol extracts from Schinus terebinthifolius and Croton urucurana against $C$. albicans biofilm in in vitro studies (Shuford et al. 2005; Sangetha et al. 2009; Barbieri et al. 2014).

Besides plant extracts and EOs, the antimicrobial activity of small molecules against yeast biofilm formation has also been evaluated (Bou Zeidan et al. 2013). In particular, Bou Zeidan et al. (2014) reported the reduction of biofilm formation by S. cerevisiae when L-histidine was added as the sole nitrogen source. Similarly, Szafranski-Schneider et al. (2012) found that L-histidine modulates biofilm formation in C. albicans. Zara et al. (2019a) found that the addition of histidine, arginine, lysine, cysteine, tryptophan, phenylalanine, and threonine all reduce biofilm formation in $S$. cerevisiae. In particular, arginine and cysteine were the most effective against biofilm formation. In accordance, Abd et al. (2014) found that $\mathrm{N}$-acetyl cysteine inhibits and removes $C$. albicans biofilms. Sanna et al. (2012) showed that methionine induces morphology changes in Pichia fermentans through the activation of a putative methionine-sensing machinery involving phospholipase C (Sanna et al. 2014).

Another interesting approach to the fight against fungal biofilm involves interfering with the normal functioning of quorumsensing molecules (QSMs). QSMs have been described in bacteria and in yeast, where they allow cell-cell communication among the members of a microbial community (Albuquerque and Casadevall 2012). In particular, Candidasecreted QSMs induce phenotypic adaptations that include morphological changes, the secretion of virulence factors, and biofilm formation (Kruppa 2009; Deveau and Hogan 2011). Farnesol and tyrosol are the two most studied QSMs. Farnesol accumulation can block the yeasthyphal transition of $C$. albicans at high cell densities, thus preventing biofilm formation (Mosel et al. 2005). Recently, the effect of farnesol against $C$. tropicalis and other yeasts isolated from fruit juice filtration membranes in mono- and multispecies biofilms was assessed (Agustín et al. 2019). Similarly, the combination of tyrosol with other antifungals (amphotericin B, itraconazole, and fluconazole) showed a synergistic effect against $C$. albicans and $C$. tropicalis biofilms (Sebaa et al. 2019). By contrast, nitric oxide (NO), a recognized QSM, enhanced the biofilm formation of $S$. cerevisiae through FLO11-independent mechanisms (Yan and Bassler 2019). Finally, microbial derived molecules (killer toxins) have also been considered for the inhibition of yeast biofilm formation, but the efficacy of their effect remains rather controversial. While it has been suggested that the spatial use by biofilms represents a sort of protective armor against yeast killer toxins, other authors observed that Aureobasidium, Pseudozyma, Ustilago, and Candida spp. exert an extensive biofilm inhibitory effect on Candida that is very likely due to the secretion of killer toxins (Mannazzu et al. 2019).

\section{Conclusions}

Recent scientific evidence has shown that yeast biofilms constitute a serious economic and health issue in food manufacturing. In addition, it is now well-ascertained that in many or most natural environments and foods, biofilms are formed by mixed bacterial, yeast, and fungal populations. For these reasons, one of the major challenges in current food microbiology is the identification of novel tools capable of preventing or removing mixed species biofilms. In this respect, the knowledge of microbial interactions and the identification of the genetic and environmental mechanisms involved in yeast biofilm formation could lead to the development of new biocontrol agents. Since the effectiveness of plant essential oils, quorum-sensing molecules, small molecules, and killer toxins has mostly been demonstrated in vitro using over-simplified systems, further studies are required to directly assess their activities on food matrices and the environment.

Acknowledgements Open access funding provided by Università degli Studi di Sassari within the CRUI-CARE Agreement. GZ gratefully acknowledges Sardinia Regional Government for the financial support of his research grant (Regional Operational Program of the European Social Fund (ROP ESF) 2014-2020-C.U.P. J86C18000270002). GZ and SZ also thank the "Fondo Regionale per la Ricerca 2019" of the University of Sassari for having partially supported this research. Finally, we thank Stephanie Parsley of Eureka Editing for the English language revision.

Funding This research was partially funded by PRIN 2017, Grant Number 2017B7MMJ5_001.

Open Access This article is licensed under a Creative Commons Attribution 4.0 International License, which permits use, sharing, adaptation, distribution and reproduction in any medium or format, as long as you give appropriate credit to the original author(s) and the source, provide a link to the Creative Commons licence, and indicate if changes were made. The images or other third party material in this article are included in the article's Creative Commons licence, unless indicated otherwise in a credit line to the material. If material is not included in the article's Creative Commons licence and your intended use is not permitted by statutory regulation or exceeds the permitted use, you will need to obtain permission directly from the copyright holder. To view a copy of this licence, visit http://creativecommons.org/licenses/by/4.0/.

\section{References}

Abd E-BRM, Ela DMMAE, Gad GFM (2014) N-acetylcysteine Inhibits and eradicates Candida albicans biofilms. Am J Infect Dis Microbiol 2:122-130. https://doi.org/10.12691/ajidm-2-5-5

Agustín MDR, Viceconte FR, Vela Gurovic MS, Costantino A, Brugnoni LI (2019) Effect of quorum sensing molecules and natamycin on biofilms of and other yeasts isolated from industrial juice filtration membranes. J Appl Microbiol 126(6):1808-1820 
Albuquerque P, Casadevall A (2012) Quorum sensing in fungi-a review. Med Mycol 50:337-345. https://doi.org/10.3109/13693 786.2011.652201

Alejo-Armijo A, Glibota N, Frías MP et al (2017) Antimicrobial and antibiofilm activities of procyanidins extracted from laurel wood against a selection of foodborne microorganisms. Int J Food Sci Technol 52:679-686. https://doi.org/10.1111/ijfs.13321

Alvarez-Ordóñez A, Coughlan LM, Briandet R, Cotter PD (2019) Biofilms in food processing environments: challenges and opportunities. Annu Rev Food Sci Technol 10:173-195. https://doi. org/10.1146/annurev-food-032818-121805

Arroyo-López FN, Bautista-Gallego J, Domínguez-Manzano J et al (2012) Formation of lactic acid bacteria-yeasts communities on the olive surface during Spanish-style Manzanilla fermentations. Food Microbiol 32:295-301. https://doi.org/10.1016/j. fm.2012.07.003

Barbieri DSV, Tonial F, Lopez PVA et al (2014) Antiadherent activity of Schinus terebinthifolius and Croton urucurana extracts on in vitro biofilm formation of Candida albicans and Streptococcus mutans. Arch Oral Biol 59:887-896. https://doi.org/10.1016/j. archoralbio.2014.05.006

Benítez-Cabello A, Romero-Gil V, Rodríguez-Gómez F et al (2015) Evaluation and identification of poly-microbial biofilms on natural green Gordal table olives. Antonie Van Leeuwenhoek 108:597-610. https://doi.org/10.1007/s10482-015-0515-2

Bojsen RK, Andersen KS, Regenberg B (2012) Saccharomyces cerevisiae - a model to uncover molecular mechanisms for yeast biofilm biology. FEMS Immunol Med Microbiol 65:169-182. https://doi.org/10.1111/j.1574-695X.2012.00943.x

Bou Zeidan M, Carmona L, Zara S, Marcos JF (2013) FLO11 gene is involved in the interaction of flor strains of Saccharomyces cerevisiae with a biofilm-promoting synthetic hexapeptide. Appl Environ Microbiol 79:6023-6032. https://doi.org/10.1128/ AEM.01647-13

Bou Zeidan M, Zara G, Viti C et al (2014) L-histidine inhibits biofilm formation and FLO11-associated phenotypes in Saccharomyces cerevisiae flor yeasts. PLoS ONE 9:e112141. https://doi. org/10.1371/journal.pone.0112141

Brugnoni LI, Lozano JE, Cubitto MA (2007) Potential of yeast isolated from apple juice to adhere to stainless steel surfaces in the apple juice processing industry. Food Res Int 40:332-340. https://doi. org/10.1016/j.foodres.2006.10.003

Brugnoni LI, Cubitto MA, Lozano JE (2011) Biofilm formation under laminar flow conditions of yeast isolated from an apple juice processing plant. J Food Process Eng 34:49-66. https://doi.org/ $10.1111 / \mathrm{j} .1745-4530.2008 .00336 . x$

Brugnoni LI, Tarifa MC, Lozano JE, Genovese D (2014) In situ rheology of yeast biofilms. Biofouling 30:1269-1279. https://doi. org/10.1080/08927014.2014.981165

Bruneton J (1999) Pharmacognosy: phytochemistry, medicinal plants, subsequent editions. Intercept Ltd, Londres

Camiolo S, Porru C, Benítez-Cabello A et al (2017) Genome overview of eight Candida boidinii strains isolated from human activities and wild environments. Stand Genom Sci 12:70-75. https://doi. org/10.1186/s40793-017-0281-z

Cappitelli F, Polo A, Villa F (2014) Biofilm formation in food processing environments is still poorly understood and controlled. Food Eng Rev 6:29-42. https://doi.org/10.1007/s12393-014-9077-8

Chambers LD, Stokes KR, Walsh FC, Wood RJK (2006) Modern approaches to marine antifouling coatings. Surf Coat Technol 201:3642-3652. https://doi.org/10.1016/j.surfcoat.2006.08.129

Coi AL, Bigey F, Mallet S et al (2017) Genomic signatures of adaptation to wine biological ageing conditions in biofilm-forming flor yeasts. Mol Ecol 26:2150-2166. https://doi.org/10.1111/ mec. 14053
D’Amato S, Serio A, López CC, Paparella A (2018) Hydrosols: biological activity and potential as antimicrobials for food applications. Food Control 86:126-137. https://doi.org/10.1016/j.foodc ont.2017.10.030

David-Vaizant V, Alexandre H (2018) Flor yeast diversity and dynamics in biologically aged wines. Front Microbiol 9:2235. https:// doi.org/10.3389/fmicb.2018.02235

De Hoog GS, Zeng JS, Harrak MJ, Sutton DA (2006) Exophiala xenobiotica sp. nov., an opportunistic black yeast inhabiting environments rich in hydrocarbons. Antonie Van Leeuwenhoek 90:257-268. https://doi.org/10.1007/s10482-006-9080-z

Deák T (1991) Foodborne yeasts. Adv Appl Microbiol 36:179-278. https://doi.org/10.1016/s0065-2164(08)70454-4

Deveau A, Hogan DA (2011) Linking quorum sensing regulation and biofilm formation by Candida albicans. Methods Mol Biol Clifton NJ 692:219-233. https://doi.org/10.1007/978-1-60761 $-971-0 \_16$

Edziri H, Jaziri R, Chehab H, Verschaeve L, Flamini G, Boujnah D, Hammami M, Aouni M, Mastouri M (2019) A comparative study on chemical composition, antibiofilm and biological activities of leaves extracts of four Tunisian olive cultivars. Heliyon 5(5): $\mathrm{e} 01604$

Fancello F, Multineddu C, Santona M et al (2020) Bacterial biodiversity of extra virgin olive oils and their potential biotechnological exploitation. Microorganisms 8:97. https://doi.org/10.3390/micro organisms 8010097

Fanning S, Mitchell AP (2012) Fungal biofilms. PLoS Pathog. https:// doi.org/10.1371/journal.ppat.1002585

Faria-Oliveira F, Carvalho J, Belmiro CLR et al (2015) Elemental biochemical analysis of the polysaccharides in the extracellular matrix of the yeast Saccharomyces cerevisiae. J Basic Microbiol 55:685-694. https://doi.org/10.1002/jobm.201400781

Flemming H-C, Wingender J (2010) The biofilm matrix. Nat Rev Microbiol 8:623-633. https://doi.org/10.1038/nrmicro2415

Fox EP, Bui CK, Nett JE et al (2015) An expanded regulatory network temporally controls Candida albicans biofilm formation. Mol Microbiol 96:1226-1239. https://doi.org/10.1111/mmi.13002

Fugelsang KC, Edwards CG (2007) Wine spoilage. Wine microbiology: practical applications and procedures. Springer, Boston, pp 162-179

Gattlen J, Zinn M, Guimond S et al (2011) Biofilm formation by the yeast Rhodotorula mucilaginosa: process, repeatability and cell attachment in a continuous biofilm reactor. Biofouling 27:979991. https://doi.org/10.1080/08927014.2011.619657

Girardot M, Imbert C (2016) Natural sources as innovative solutions against fungal biofilms. Adv Exp Med Biol 931:105-125. https ://doi.org/10.1007/5584_2016_12

Glasenapp Y, Lucas C, Wöltje T et al (2019) Anti-adhesion activity of tannins isolated from the mangrove Laguncularia racemosa. Chem Biodivers 16:e1800632. https://doi.org/10.1002/ cbdv.201800632

Goode KR, Asteriadou K, Fryer PJ et al (2010) Characterising the cleaning mechanisms of yeast and the implications for cleaning in place (CIP). Food Bioprod Process 88:365-374. https://doi. org/10.1016/j.fbp.2010.08.005

Gulati M, Nobile CJ (2016) Candida albicans biofilms: development, regulation, and molecular mechanisms. Microbes Infect Inst Pasteur 18:310-321. https://doi.org/10.1016/j.micinf.2016.01.002

Husband S, Fish KE, Douterelo I, Boxall J (2016) Linking discolouration modelling and biofilm behaviour within drinking water distribution systems. Water Supply 16:942-950. https://doi. org/10.2166/ws.2016.045

Hutzler M, Riedl R, Koob J, Jacob F (2012) Fermentation and spoilage yeasts and their relevance for the beverage industry - a review. Brew Sci\&nbsp; 65:33-52 
Joseph CML, Kumar G, Su E, Bisson LF (2007) Adhesion and biofilm production by wine isolates of Brettanomyces bruxellensis. Am J Enol Vitic 58:373-378

Karunanithi S, Vadaie N, Chavel CA et al (2010) Shedding of the mucin-like flocculin Flo11p reveals a new aspect of fungal adhesion regulation. Curr Biol CB 20:1389-1395. https://doi. org/10.1016/j.cub.2010.06.033

Kruppa M (2009) Quorum sensing and Candida albicans. Mycoses 52:1-10. https://doi.org/10.1111/j.1439-0507.2008.01626.x

Kumari P, Arora N, Chatrath A et al (2019) Delineating the biofilm inhibition mechanisms of phenolic and aldehydic terpenes against Cryptococcus neoformans. ACS Omega 4:17634-17648. https://doi.org/10.1021/acsomega.9b01482

Kurtzman CP, Fell JW, Boekhout T (2011) The yeasts: a taxonomic study, 5th edn. Elsevier Science Ltd, Amsterdam

Laitila A, Sarlin T, Raulio M et al (2011) Yeasts in malting, with special emphasis on Wickerhamomyces anomalus (synonym Pichia anomala). Antonie Van Leeuwenhoek 99:75-84. https://doi. org/10.1007/s10482-010-9511-8

Lattif AA, Chandra J, Chang J et al (2008) Proteomics and pathway mapping analyses reveal phase-dependent over-expression of proteins associated with carbohydrate metabolic pathways in Candida albicans biofilms. Open Proteom J 1:5-26. https://doi. org/10.2174/1875039700801010005

Lattif AA, Mukherjee PK, Chandra J et al (2011) Lipidomics of Candida albicans biofilms reveals phase-dependent production of phospholipid molecular classes and role for lipid rafts in biofilm formation. Microbiology 157:3232-3242. https://doi. org/10.1099/mic.0.051086-0

Legras J-L, Moreno-Garcia J, Zara S et al (2016) Flor yeast: new perspectives beyond wine aging. Front Microbiol 7:503. https://doi. org/10.3389/fmicb.2016.00503

Lipke PN (2018) What we do not know about fungal cell adhesion molecules. J Fungi Basel Switz 4:59. https://doi.org/10.3390/ jof 4020059

Livas D, Almering MJ, Daran J-M et al (2011) Transcriptional responses to glucose in Saccharomyces cerevisiae strains lacking a functional protein kinase A. BMC Genom 12:405. https:// doi.org/10.1186/1471-2164-12-405

Lohse MB, Gulati M, Johnson AD, Nobile CJ (2018) Development and regulation of single- and multi-species Candida albicans biofilms. Nat Rev Microbiol 16:19-31. https://doi.org/10.1038/ nrmicro.2017.107

Lyon DY, Brown D, Sundstrom ER, Alvarez PJJ (2008) Assessing the antibiofouling potential of a fullerene-coated surface. Int Biodeterior Biodegrad 62:475-478. https://doi.org/10.1016/j.ibiod .2007.11.007

Mannazzu I, Domizio P, Carboni G et al (2019) Yeast killer toxins: from ecological significance to application. Crit Rev Biotechnol 39:603-617. https://doi.org/10.1080/07388551.2019.1601679

Martillanes S, Rocha-Pimienta J, Cabrera-Bañegil M et al (2017) Application of phenolic compounds for food preservation: food additive and active packaging. Phenol Compd-Biol Act. https:// doi.org/10.5772/66885

Moreno-García J, Coi AL, Zara G et al (2018) Study of the role of the covalently linked cell wall protein (Ccw $14 \mathrm{p})$ and yeast glycoprotein (Ygp1p) within biofilm formation in a flor yeast strain. FEMS Yeast Res 18:2. https://doi.org/10.1093/femsyr/foy005

Mosel DD, Dumitru R, Hornby JM et al (2005) Farnesol concentrations required to block germ tube formation in Candida albicans in the presence and absence of serum. Appl Environ Microbiol 71:4938-4940. https://doi.org/10.1128/ AEM.71.8.4938-4940.2005

Nguyen PV, Hlaváček O, Maršíková J et al (2018) Cyc8p and Tup1p transcription regulators antagonistically regulate Flo11p expression and complexity of yeast colony biofilms. PLoS Genet 14:e1007495. https://doi.org/10.1371/journal.pgen.1007495

Paramonova E, Krom BP, van der Mei HC et al (2009) Hyphal content determines the compression strength of Candida albicans biofilms. Microbiol Read Engl 155:1997-2003. https://doi. org/10.1099/mic.0.021568-0

Perpetuini G, Tittarelli F, Mattarelli P et al (2018) Intraspecies polymorphisms of Kluyveromyces marxianus strains from Yaghnob valley. FEMS Microbiol Lett. https://doi.org/10.1093/femsle/ fny028

Perpetuini G, Tittarelli F, Suzzi G, Tofalo R (2019) Cell wall surface properties of Kluyveromyces marxianus strains from dairyproducts. Front Microbiol 10:79. https://doi.org/10.3389/fmicb .2019 .00079

Petretto GL, Fancello F, Zara S et al (2014) Antimicrobial activity against beneficial microorganisms and chemical composition of essential oil of Mentha suaveolens ssp. insularis grown in Sardinia. J Food Sci 79:M369-M377. https://doi. org/10.1111/1750-3841.12343

Porru C, Rodríguez-Gómez F, Benítez-Cabello A et al (2018) Genotyping, identification and multifunctional features of yeasts associated to Bosana naturally black table olive fermentations. Food Microbiol 69:33-42. https://doi.org/10.1016/j.fm.2017.07.010

Pozo-Bayón M, Moreno-Arribas MV (2011) Sherry wines. Adv Food Nutr Res 63:17-40. https://doi.org/10.1016/B978-0-12-38492 7-4.00002-6

Rajkowska K, Nowicka-Krawczyk P, Kunicka-Styczyńska A (2019) Effect of clove and thyme essential oils on Candida biofilm formation and the oil distribution in yeast cells. Mol Basel Switz. https://doi.org/10.3390/molecules24101954

Ramage G, Robertson SN, Williams C (2014) Strength in numbers: antifungal strategies against fungal biofilms. Int J Antimicrob Agents 43:114-120. https://doi.org/10.1016/j.ijantimica g.2013.10.023

Reynolds TB, Fink GR (2001) Bakers' yeast, a model for fungal biofilm formation. Science 291:878-881. https://doi.org/10.1126/scien ce. 291.5505 .878

Riedl R, Fütterer J, Goderbauer P et al (2019) Combined yeast biofilm screening - characterization and validation of yeast related biofilms in a brewing environment with combined cultivation and specific real-time PCR screening of selected indicator species. J Am Soc Brew Chem 77:99-112. https://doi.org/10.1080/03610 470.2019.1579036

Rola K, Osyczka P, Kafel A (2016) Different heavy metal accumulation strategies of epilithic lichens colonising artificial post-smelting wastes. Arch Environ Contam Toxicol 70:418-428. https://doi. org/10.1007/s00244-015-0180-5

Salo S, Wirtanen G (2005) Disinfectant efficacy on foodborne spoilage yeast strains. Food Bioprod Process 83:288-296. https://doi. org/10.1205/fbp.04317

Sangetha S, Zuraini Z, Suryani S, Sasidharan S (2009) In situ TEM and SEM studies on the antimicrobial activity and prevention of Candida albicans biofilm by Cassia spectabilis extract. Micron 40:439-443. https://doi.org/10.1016/j.micron.2009.01.003

Sanna ML, Zara G, Zara S et al (2014) A putative phospholipase C is involved in Pichia fermentans dimorphic transition. Biochim Biophys Acta 1840:344-349. https://doi.org/10.1016/j.bbage n.2013.09.030

Sanna ML, Zara S, Zara G et al (2012) Pichia fermentans dimorphic changes depend on the nitrogen source. Fungal Biol 116:769777. https://doi.org/10.1016/j.funbio.2012.04.008

Santona M, Sanna ML, Multineddu C et al (2018) Microbial biodiversity of Sardinian oleic ecosystems. Food Microbiol 70:65-75. https://doi.org/10.1016/j.fm.2017.09.004 
Schön K, Schornsteiner E, Dzieciol M et al (2016) Microbial communities in dairy processing environment floor-drains are dominated by product-associated bacteria and yeasts. Food Control 70:210-215. https://doi.org/10.1016/j.foodcont.2016.05.057

Sebaa S, Boucherit-Otmani Z, Courtois P (2019) Effects of tyrosol and farnesol on Candida albicans biofilm. Mol Med Rep 19:32013209. https://doi.org/10.3892/mmr.2019.9981

Shahzad M, Sherry L, Rajendran R et al (2014) Utilising polyphenols for the clinical management of Candida albicans biofilms. Int $\mathbf{J}$ Antimicrob Agents 44:269-273. https://doi.org/10.1016/j.ijant imicag.2014.05.017

Shuford JA, Steckelberg JM, Patel R (2005) Effects of fresh garlic extract on Candida albicans biofilms. Antimicrob Agents Chemother 49:473. https://doi.org/10.1128/AAC.49.1.473.2005

Snyder AB, Worobo RW (2018) The incidence and impact of microbial spoilage in the production of fruit and vegetable juices as reported by juice manufacturers. Food Control 85:144-150. https ://doi.org/10.1016/j.foodcont.2017.09.025

Srey S, Jahid IK, Ha S-D (2013) Biofilm formation in food industries: a food safety concern. Food Control 31:572-585. https://doi. org/10.1016/j.foodcont.2012.12.001

Storgårds E, Tapani K, Hartwall P et al (2006) Microbial attachment and biofilm formation in brewery bottling plants. J Am Soc Brew Chem 64:8-15. https://doi.org/10.1094/ASBCJ-64-0008

Sugumar S, Singh S, Mukherjee A, Chandrasekaran N (2016) Nanoemulsion of orange oil with non ionic surfactant produced emulsion using ultrasonication technique: evaluating against food spoilage yeast. Appl Nanosci 6(1):113-120

Szafranski-Schneider E, Swidergall M, Cottier F et al (2012) Msb2 shedding protects Candida albicans against antimicrobial peptides. PLoS Pathog. https://doi.org/10.1371/journal.ppat.10025 01

Takó M, Kerekes EB, Zambrano C et al (2020) Plant phenolics and phenolic-enriched extracts as antimicrobial agents against foodcontaminating microorganisms. Antioxid Basel Switz. https:// doi.org/10.3390/antiox9020165

Tan HV, Tay ST (2011) Anti-Candida activity and biofilm inhibitory effects of secreted products of tropical environmental yeasts. Trop Biomed 28:175-180

Tarifa MC, Lozano JE, Brugnoni LI (2017) Candida krusei isolated from fruit juices ultrafiltration membranes promotes colonization of Escherichia coli $\mathrm{O} 157: \mathrm{H} 7$ and Salmonella enterica on stainless steel surfaces. J Microbiol Seoul Korea 55:96-103. https:// doi.org/10.1007/s12275-017-6300-3

Tenore GC, Novellino E, Basile A (2012) Nutraceutical potential and antioxidant benefits of red pitaya (Hylocereus polyrhizus) extracts. J Funct Foods 4:129-136. https://doi.org/10.1016/j. jff.2011.09.003

Tsang PW-K, Bandara HMHN, Fong W-P (2012) Purpurin suppresses Candida albicans biofilm formation and hyphal development. PLoS ONE 7:e50866. https://doi.org/10.1371/journ al.pone.0050866

Van Mulders SE, Ghequire M, Daenen L et al (2010) Flocculation gene variability in industrial brewer's yeast strains. Appl Microbiol Biotechnol 88:1321-1331. https://doi.org/10.1007/s0025 3-010-2843-5

Van Nguyen P, Plocek V, Váchová L, Palková Z (2020) Glucose, Cyc8p and Tup1p regulate biofilm formation and dispersal in wild Saccharomyces cerevisiae. NPJ Biofilms Microbiomes 6:1-10. https ://doi.org/10.1038/s41522-020-0118-1

Vinod PK, Sengupta N, Bhat PJ, Venkatesh KV (2008) Integration of global signaling pathways, cAMP-PKA, MAPK and TOR in the regulation of FLO11. PLoS ONE 3:e1663. https://doi. org/10.1371/journal.pone.0001663

Vitzilaiou E, Stoica IM, Knøchel S (2019) Microbial biofilm communities on reverse osmosis membranes in whey water processing before and after cleaning. J Membr Sci 587:117174. https://doi. org/10.1016/j.memsci.2019.117174

Vopálenská I, St’ovícek V, Janderová B et al (2010) Role of distinct dimorphic transitions in territory colonizing and formation of yeast colony architecture. Environ Microbiol 12:264-277. https ://doi.org/10.1111/j.1462-2920.2009.02067.x

Wu S, Wang Y, Liu N et al (2017) Tackling fungal resistance by biofilm inhibitors. J Med Chem 60:2193-2211. https://doi.org/10.1021/ acs.jmedchem.6b01203

Yan J, Bassler BL (2019) Surviving as a community: antibiotic tolerance and persistence in bacterial biofilms. Cell Host Microbe 26:15-21. https://doi.org/10.1016/j.chom.2019.06.002

Zara G, Goffrini P, Lodi T et al (2012) FLO11 expression and lipid biosynthesis are required for air-liquid biofilm formation in a $\mathrm{Sac}$ charomyces cerevisiae flor strain. FEMS Yeast Res 12:864-866. https://doi.org/10.1111/j.1567-1364.2012.00831.x

Zara S, Antonio Farris G, Budroni M, Bakalinsky AT (2002) HSP12 is essential for biofilm formation by a Sardinian wine strain of S. cerevisiae. Yeast Chichester Engl 19:269-276. https://doi. org/10.1002/yea.831

Zara S, Bakalinsky AT, Zara G et al (2005) FLO11-based model for airliquid interfacial biofilm formation by Saccharomyces cerevisiae. Appl Environ Microbiol 71:2934-2939. https://doi.org/10.1128/ AEM.71.6.2934-2939.2005

Zara G, Bardi L, Belviso S et al (2008) Correlation between cell lipid content, gene expression and fermentative behaviour of two Saccharomyces cerevisiae wine strains. J Appl Microbiol 104:906914. https://doi.org/10.1111/j.1365-2672.2007.03608.x

Zara G, Zara S, Pinna C et al (2009) FLO11 gene length and transcriptional level affect biofilm-forming ability of wild flor strains of Saccharomyces cerevisiae. Microbiol Read Engl 155:3838-3846. https://doi.org/10.1099/mic.0.028738-0

Zara S, Gross MK, Zara G et al (2010) Ethanol-independent biofilm formation by a flor wine yeast strain of Saccharomyces cerevisiae. Appl Environ Microbiol 76:4089-4091. https://doi. org/10.1128/AEM.00111-10

Zara G, Budroni M, Mannazzu I, Zara S (2011) Air-liquid biofilm formation is dependent on ammonium depletion in a Saccharomyces cerevisiae flor strain. Yeast Chichester Engl 28:809-814. https:// doi.org/10.1002/yea.1907

Zara G, Bou Zeidan M, Fancello F et al (2019a) The administration of L-cysteine and L-arginine inhibits biofilm formation in wildtype biofilm-forming yeast by modulating FLO11 gene expression. Appl Microbiol Biotechnol 103:7675-7685. https://doi. org/10.1007/s00253-019-09996-5

Zara G, van Vuuren HJJ, Mannazzu I et al (2019b) Transcriptomic response of Saccharomyces cerevisiae during fermentation under oleic acid and ergosterol depletion. Fermentation 5:57. https:// doi.org/10.3390/fermentation5030057

Publisher's Note Springer Nature remains neutral with regard to jurisdictional claims in published maps and institutional affiliations. 